특집논문-09-14-4-03

$$
\begin{gathered}
\text { 시점변화에 적응적인 보행자 유동 속도 측정 } \\
\text { 이 광 국(a) }{ }^{\ddagger} \text {, 윤 자 영a), 김 재 준a), 김 회 율a) }
\end{gathered}
$$

\title{
A Method of Pedestrian Flow Speed Estimation Adaptive to Viewpoint Changes
}

\author{
Gwang-Gook Lee $^{\text {a) }}$, Ja-Young Yoon ${ }^{\text {b) }}$, Jae-Jun Kim ${ }^{\text {b) }}$, and Whoi-Yul Kim ${ }^{\text {a) }}$
}

요 약

본 논문은 일반적인 영상 감시 비디오의 입력으로부터 영상 내 보행자들의 유동 속도를 측정하는 방법을 제안한다. 제안한 방 법은 연속된 프레임 간에 얻어진 움직임 벡터로부터 실세계(real world)에서 보행자들의 이동량의 크기를 예측하고, 이를 통해 영 상 내 보행자들의 평균 이동 속도를 측정한다. 제안한 방법에서는 이를 위해 영상 내 화소 단위를 실세계의 물리 단위(미터)로 변 환하기 위한 변환 인자를 정의하였다. 또한, 정확한 속도 추정을 위해 카메라 투영 과정에서 잃어버리게 되는 실세계 움직임의 높 이 정보를 시뮬레이션 실험을 통해 통계적으로 추정하였다. 제안한 방법은 카메라 매개변수를 속도 추정 과정에서 명시적으로 분 리하여 표현하기 때문에 기존의 유동 속도 추정 방법과 달리 영상의 환경 변화에 적응적으로 대응할 수 있는 장점이 있다. 제안 한 방법의 검증을 위하여 시뮬레이션 영상과 실제 영상에 대하여 실험이 이루어졌다. 실험 결과 제안한 방법은 시뮬레이션 영상 에서 약 $0.08 \mathrm{~m} / \mathrm{s}$ 의 오차로 속도를 추정할 수 있었으며, 실제 영상에 대해서도 기대할 수 있는 결과를 보여주었다.

\section{Abstract}

This paper proposes a method to estimate the flow speed of pedestrians in surveillance videos. In the proposed method, the average moving speed of pedestrians is measured by estimating the size of real-world motion from the observed motion vectors. For this purpose, a pixel-to-meter conversion factor is introduced which is calculated from camera parameters. Also, the height information, which is missing because of camera projection, is predicted statistically from simulation experiments. Compared to the previous works for flow speed estimation, our method can be applied to various camera views because it separates scene parameters explicitly. Experiments are performed on both simulation image sequences and real video. In the experiments on simulation videos, the proposed method estimated the flow speed with average error of about $0.08 \mathrm{~m} / \mathrm{s}$. The proposed method also showed promising results for the real video.

Keyword : 지능형 영상 감시, 유동 속도 측정, $\mathrm{CCTV}$

a) 한양대학교 전자통신컴퓨터공학부

Dept. of Electronics and Computer Engineering, Hanyang University b) 한양대학교 건축환경공학부

Dept. of Sustainable Architectural Engineering, Hanyang University \# 교신저자 : 이광국(gglee@vision.hanyang.ac.kr)

※ 본 연구는 국토해양부 첨단도시개발사업의 연구비지원(06 건설핵심 D06)에 의해 수행되었습니다.

· 접수일(2009년3월14일),수정일(2009년7월1일),게재확정일(2009년7월1일)

\section{I. 서 론}

대형 복합 건축물 (multiplex building)의 증대와 하드웨 어의 발달, 영상 신호처리 기술의 발전과 함께 지난 10 여 년간 지능형 영상 감시 시스템 개발을 위해 다양한 노력이 
있어왔다. 영상의 단순 기록만을 수행하기 때문에 사고 발 생 이후에 사실 확인의 목적으로 사용되는 전통적인 영상 감시 시스템과 달리 지능형 영상 감시 시스템은 CCTV로부 터 획득된 입력 영상을 해석하여 관심 사건을 검출하고, 경 고를 발생시킴으로서 사고 발생을 미연에 방지하는 것을 그 목적으로 한다. 이러한 지능형 영상 감시 응용의 예로는 군중 밀도 측정 ${ }^{[1-3]}$, 이상 사건 감지 ${ }^{[4]}$ 또는 버려진 물체 검 출 $^{[5]}$ 등을 들 수 있다. 기존의 지능형 영상 감시에 대해 이 와 같이 다양한 연구들이 이루어졌지만, 보행자의 유동 속 도의 측정은 그 중요성에 비해서 상대적으로 적은 관심을 받아왔다. 유동 속도는 대형 건축물 내에서 전역적 관점에 서 이상 사건 감지를 위한 중요한 수단을 제공하며, 또 영상 감시 이외에 마케팅 관점에서 상권의 가치 분석 등의 중요 하게 이용되며 대형 건축물에서 요구되는 피난 계획의 설 계 등에 필요한 보행자 통행 모델(pedestrian traffic model) 의 개발에 필수적인 정보로 활용될 수 있다 ${ }^{[6]}$.

본 논문에서는 $\mathrm{CCTV}$ 에 의해 획득된 일반적인 감시 영상 에서 보행자의 유동 속도(pedestrian flow speed)를 계산하 기 위한 방법을 제안한다. 유동 속도는 영상 내에서 이동하 는 보행자들의 평균적 이동 속도에 의해 계산되며, 본 논문 에서는 특히 보행자들이 단일 통로를 양방향으로 이동하는 상황을 가정하였다. 제안한 방법에서 유동 속도의 측정은 영 상 영역(image domain)에서 얻어진 움직임 벡터를 물리 영 역(physical domain)으로 변환함으로써 이루어진다. 이를 위해 카메라 기하(camera geometry)로부터 직접적으로 계 산되는 화소-미터 변환 계수(pixel-to-meter conversion factor)를 정의하였다. 또한 카메라 투영 과정에서 발생하는 움 직임 벡터의 모호성을 해결하기 위하며 영상 내 움직임 벡터 의 실세계에서의 높이 정보를 통계적인 방법을 통해 추정하 였다. 제안한 방법은 카메라의 매개 변수를 유동 속도 계산 과정에서 분리하여 표현하고 있기 때문에, 다양한 각도를 갖 는 카메라 영상에 쉽게 대응이 가능하다. 또한 제안한 방법 은 별도의 객체 검출 및 추적 과정을 포함하지 않고 움직임 벡터만을 이용하여 유동 속도를 추정하기 때문에 연산량이 적어 실제 응용에 쉽게 활용될 수 있는 장점을 가지고 있다.

본 논문은 구성은 다음과 같이 구성되어 있다. 2 장에서는 제안한 방법의 관련 연구를 소개하며, 3 장에서는 제안한 이
동 속도 측정 방법에 대하여 설명이 이어진다. 4장에서는 카 메라 투영으로 인한 움직임 벡터의 모호성을 해결하기 위한 시뮬레이션 실험에 대해서 소개된다. 제안한 방법의 실험 결 과는 5장에서 나타나며, 마지막으로 6장에서 결론을 맺는다.

\section{II. 관련 연구}

지능화된 영상 감시에 대한 관심이 높아지면서 공공장소 에서 유동량 분석과 관련한 연구들이 진행된 바 있다. 공공 장소에서 보행자들의 이동은 유동량의 크기, 방향 그리고 속도에 의해서 설명될 수 있으나, 기존의 연구들은 이 가운 데 대부분 그 크기에 초점을 맞추고 있다. Kong 등은 영상 에서 시점 변환에 불변한 군중 수 추정 방법을 제안하였는 데, 이 방법에서는 전경 영상(foreground image)의 경계 영 상에서 각각 blob 크기 히스토그램과 경계 방향 히스토그램 을 특징으로 추출하였으며 신경망을 이용하여 추출된 특징 으로부터 영상 내 보행자의 숫자를 예측하였다 ${ }^{[1]}$. 하지만, 이와 같이 훈련에 기반한 방법은 훈련에 사용된 영상의 양 이 충분하지 못하면 그 성능이 보장되지 않는 어려움이 있 었다. 이에 훈련을 이용하지 않는 화소수 계수에 의한 군중 수 추정 방법이 Celik등에 의해 제안된 바 있다 ${ }^{[3]}$. Kong이 나 Celik등에 의해 제안된 방법은 영상 내의 군중의 수를 추정할 수는 있으나 이를 통해 유동량을 얻어낼 수는 없는 문제점이 있다. 이에 Lee 등은 통계적인 방법을 이용하여 영상 내 유동량의 크기를 측정하는 방법을 제안하였다 ${ }^{[7]}$. 이 방법은 기존 군중 수 추정 방법과 유사하게 영상내의 특징량의 크기로부터 보행자의 숫자를 추정하는 것이지만, 가상의 문(virtual gate)을 설정하고 이 가상의 문을 지나는 특징량을 시간에 따라 누적시킴으로서 유동량의 크기를 계 산할 수 있는 장점이 있다. 이와 같이 감시 영상에서 군중의 행동을 관찰하는 기존의 연구들은 대부분 유동 속도보다는 영상 내 군중의 숫자, 즉 그 유동량의 크기에 초점을 두고 있다. 하지만, 보행자의 통행 행태 분석이 실제적 응용에 유용하게 이용되기 위해서는 유동량의 크기 뿐 아니라 평 균적인 이동 속도에 대한 분석이 함께 이루어져야 한다.

유동 속도의 측정은 입력 영상에서 보행자 개개인을 검 
출하고 추적하여 그 이동 경로를 실제 좌표로 역변환하여 속도를 계산하여 이루어질 수 있을 것이다. Teknomo 등은 보행자의 이동 흐름 (pedestrian flow)의 분석을 위한 데이 터 수집 시스템을 제안한 바 있다 ${ }^{[8]}$. 이 시스템에서는 움직 이는 영상에서 물체를 검출하고 추적하여 시간별로 위치를 기록하며, 이렇게 획득된 데이터로부터 개인의 이동 속도 나, 보행자의 평균 이동 속도와 방향 등과 같은 데이터를 획득하는 것이 가능했다. 하지만, Teknomo의 방법은 위에 서 내려다 본 (top-view) 영상 또는 그와 유사한 영상에 대 하여만 적용 가능하였으며, 낮은 각도에서 촬영된 영상에 대해서는 그 성능이 보장되지 않았다. 기존에 많은 연구에 서 제안된 바 있는 인간 검출자(human detector)들을 이용 하는 것은 이러한 입력 영상의 시점 제약의 문제를 해결하 기 위한 하나의 방법이 될 수 있을 것이다. $\mathrm{Li}$ 등은 통계적 검출자(statistical detector)에 카메라의 기하학적 정보를 이 용하여 높은 검출 성능을 얻는 인간 검출 방법을 제안한 바 있다 ${ }^{[9]}$. Beleznai 등은 배경 제거를 통해 얻어진 전경 영 상에 Mean shift 알고리즘을 적용하여 보행자를 분할하고 추적(tracking)을 통해 각 보행자의 이동 경로를 추출하는 방법을 제안한 바 있다 ${ }^{[10]}$. 하지만, 이런 검출자에 기반한 방법은 대부분 높은 계산량을 필요로 하고 실시간 수행이 어렵기 때문에 실제 영상 감시의 응용에 적용하기 어려운 문제가 있다. Shimmura 등은 영상에서 각 이동체를 검출하 거나 분리하지 않고 움직임 벡터만을 이용하여 보행자들의 이동 속도를 측정하기 위한 방법을 제안한 바 있다 ${ }^{[1]}$. 이 방법에서는 보행자들의 평균적인 이동 속도가 영상 내의 움직임 벡터의 크기로부터 측정되었으며, 영상 내의 움직 임 벡터의 크기를 실제 공간에서의 사람들의 이동 속도를 변환은 비율 인자(scaling factor)에 의해서 이루어졌다. 이 방법은 검출이나 추적 등의 과정을 포함하지 않기 때문에 낮은 연산량만으로 계산이 이루어질 수 있어 실제 응용에 적합하지만, 비율 인자가 특정 카메라 환경의 합성 영상으 로부터 얻어졌고 움직임 벡터의 크기를 실제 이동 속도로 환산하기 위해 유도된 변환식이 카메라 기하를 내포하기 때문에, 이 방법이 다른 시점의 카메라 영상에도 효과적으 로 적용될 수 있는지에 대해서는 입증되지 않았다.

본 논문에서 제안한 통행 속도 측정 방법은 Shimmura등
에 의해 제안된 방법과 유사하게 영상에서 추출된 움직임 벡터의 크기로부터 영상내 보행자들의 평균적 이동 속도 를 계산한다. 따라서, 이동 물체의 검출이나 추적 과정을 포함하지 않기 때문에 낮은 연산량으로 계산이 가능하여 실제적인 응용에 적합한 장점이 있다. 또한 제안된 방법은 Shimmura등의 방법과 달리 카메라 매개변수를 속도 예측 과정으로부터 명시적으로 분리하기 때문에, 다양한 시점의 카메라 영상에 적용 가능한 장점이 있다.

\section{III. 움직임 벡터를 통한 통행 속도 측정}

이 장에서는 제안한 보행자 유동 속도 측정 방법을 설명 한다. 그림 1 은 3 차원 공간에서 발생하는 움직임이 영상 평 면에 투영되는 예를 나타낸다. 그림에 나타난 것과 같이 실 공간 상에 어떤 움직임 $\mathrm{V}_{\mathrm{R}}$ 이 발생할 때, 이 움직임은 영상 평면 상의 움직임 벡터 $\mathrm{v}_{\mathrm{I}}$ 로써 관찰되게 된다. 제안한 방법 은 $\mathrm{V}_{\mathrm{I}}$ 로부터 $\mathrm{V}_{\mathrm{R}}$ 의 크기를 추정하고, 이를 통하여 영상 내 전체적인 유동 속도를 측정한다.

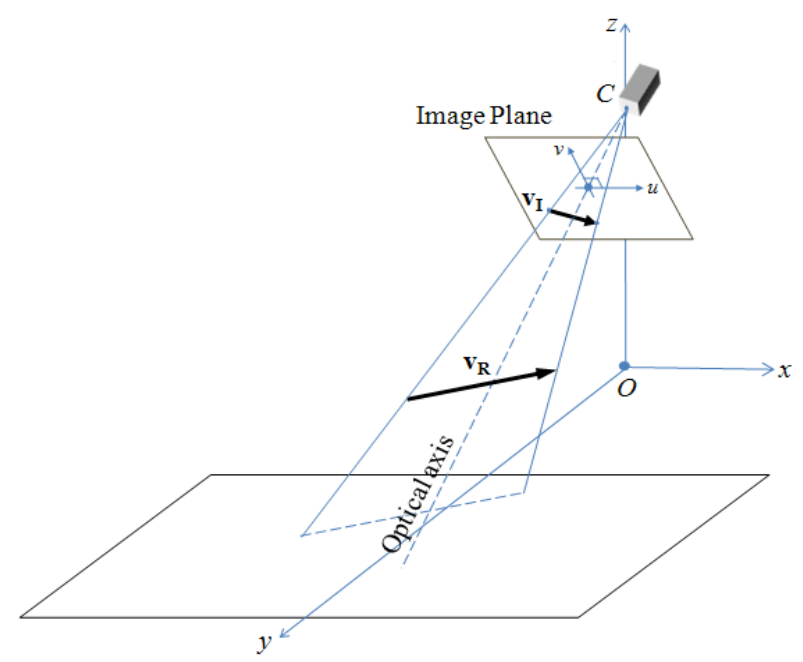

그림 1. 3 차원 공간 내 움직임의 2 차원 영상 평면으로의 투영의 예 Fig. 1. An example of camera projection from $3 \mathrm{D}$ real world to $2 \mathrm{D}$ image plane

실제 공간에서 움직임 $\mathrm{V}_{\mathrm{R}}$ 의 크기를 추정하기 위하여 제 안한 방법에서는 영상 내 화소 단위(pixel)를 물리적 단위 
(meter)로 전환하는 변환 인자(conversion factor)를 도입하 였다.

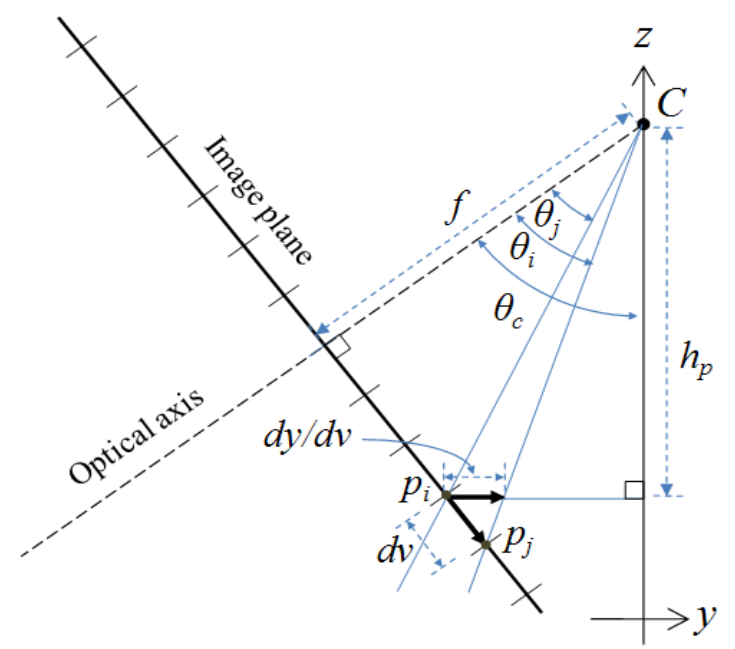

그림 2. 화소 단위의 미터 단위 변환

Fig. 2. Conversion from pixels to meters

그림 2에 나타난 것과 같이 픽셀 $p_{i}$ 에서 $p_{j}$ 까지 단위 길이 의 움직임 벡터가 관찰되었다고 가정하자. 카메라의 초점 거리 $f$ 와 경사 각도(tilt angle)가 알려져 있다고 가정하면, 각각의 화소 위치에 대하여 광축(optical axis)로부터의 각 도 $\theta_{i}$ 를 계산할 수 있다. 이러한 매개변수들에 의하여 화소미터 변환 인자는 다음의 수식 (1)과 같이 얻어질 수 있다.

$$
\frac{d y}{d v}=h_{p}\left\{\tan \left(\theta_{c}-\theta_{j}\right)-\tan \left(\theta_{c}-\theta_{i}\right)\right\}
$$

여기에서 광학 중심에서 화소 위치 까지의 수직거리 $h_{p}$ 는 다음의 수식 (2)와 같이 계산된다.

$$
h_{p}=\frac{\cos \left(\theta_{c}-\theta_{j}\right)}{\cos \theta_{j}} f
$$

그림 2에서는 수직 방향의 변환 인자 $d y / d v$ 만이 나타나 있으나, 수평 방향의 변환 인자 $d x / d u$ 는 CCD 센서의 폭을 영상의 너비로 나누어 줌으로서 간단히 계산될 수 있다. 화 소-미터 변환 인자 $d x / d u$ 와 $d y / d v$, 그리고 광학 중심(optical center)로부터의 수직 거리 $h_{p}$ 는 영상 내의 모든 화소 위치 에 대하여 미리 계산되어 저장된다.

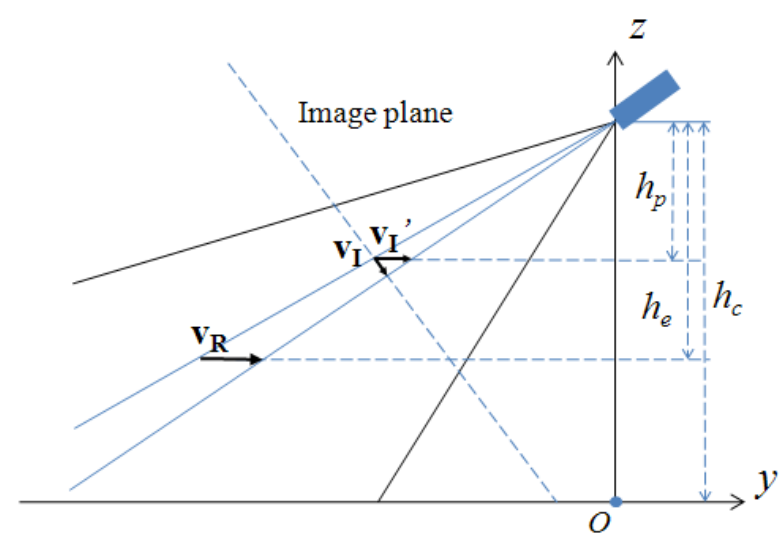

그림 3. 실공간 움직임의 크기 추정

Fig. 3. Estimation of the size of the real-world motion

계산된 변환인자를 이용하여 실공간에서의 움직임의 크 기를 그림 3에 나타난 것과 같이 삼각비를 통하여 추정할 수 있다. 그림 3에서 $\mathbf{v}_{\mathbf{I}}^{\prime}$ 은 영상 내 움직임 벡터 $\mathbf{v}_{\mathbf{I}}$ 에 화소-미 터 변환 인자를 적용하여 얻어진다. 따라서, 실공간에서 발 생한 움직임 $\mathbf{V}_{\mathbf{R}}$ 의 크기는 다음 수식 (3)에 나타난 것과 같이 계산될 수 있다.

$$
\left\|v_{R}\right\|=\frac{h_{e}}{h_{p}}\left\|v_{I}^{\prime}\right\|=\frac{h_{e}}{h_{p}}\left\|\left(v_{I}(u) \frac{d x}{d v}, v_{I}(v) \frac{d y}{d v},\right)\right\|
$$

최종적으로 시간 $t$ 에서 보행자들의 평균 이동 속도 $F S(t)$ 는 수식 (4)와 같이 모든 움직임 벡터에 대하여 추정된 실공 간의 움직임의 크기의 평균으로서 얻어진다. 이때 원근 투 영의 영향에 의해 발생한 화소 크기의 차를 보정하기 위하 여 각 움직임의 크기에 가중치 $w_{i}$ 를 적용하였다. 이 가중치 는 Kong등에 의해 제안된 군중 밀도 추정 방법 ${ }^{[1]}$ 에서와 유 사하게 초기 단계에서 사용자의 입력에 의해 지정된 밀도 지도(density map)에 의해서 얻어진다.

$$
F S(t)=\frac{\sum_{t=k}^{k+T} \sum_{i=0}^{N} w_{i}\left\|v_{\boldsymbol{R}}(i, t)\right\|}{\sum_{i=0}^{N} w_{i}}
$$


또한 유동 속도 추정 결과에서 잡음에 의한 영향을 줄이 기 위하여 유동속도가 다음의 수식 (5)와 같이 재귀 필터 (recursive filter)를 이용하여 평균화 되었으며, 이 때 $a$ 값은 실험적으로 0.02 가 선택되었다.

$$
\overline{F S(t)}=(1-\alpha) \overline{F S(t-1)}+\alpha F S(t)
$$

\section{IV. 실공간 움직임의 높이 추정}

앞의 III장에서 소개된 방법을 통하여 움직임 벡터의 크 기로부터 보행자들의 이동 속도를 측정하는 것이 가능하지 만, 여기에는 수식 (3)에 나타난 카메라와 실공간 움직임 사이의 수직 거리 $h_{e}$ 가 알려져 있지 않다는 문제가 있다.

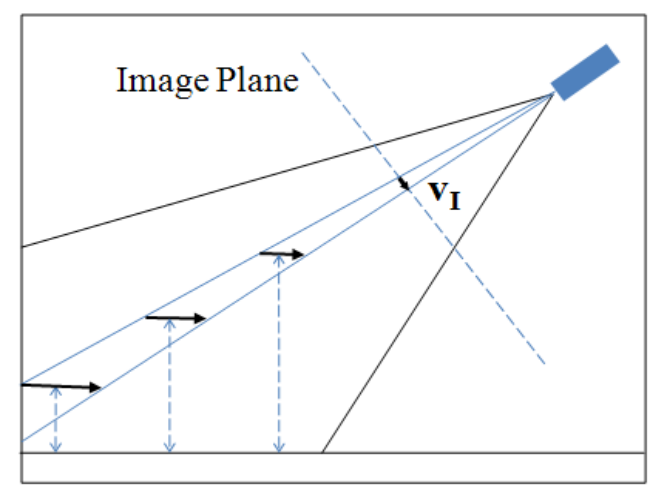

(a)

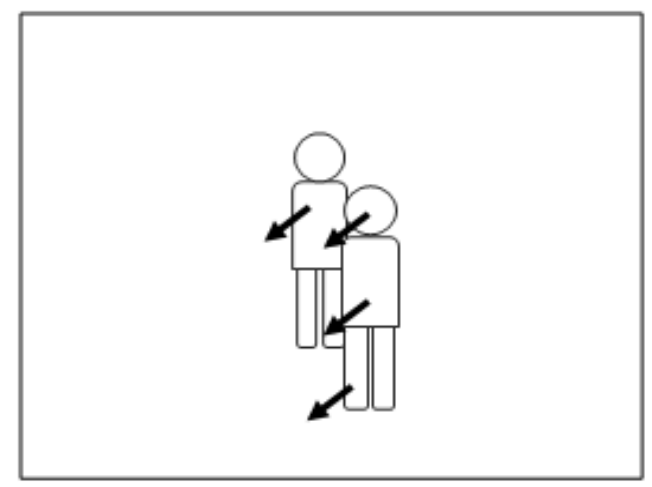

(c)
이는 영상에서 얻어진 움직임 벡터는 카메라 투영에 의해 깊이 (카메라로부터의 물체까지의 거리) 또는 실공간에서 의 높이 정보를 잃어버리기 때문이다. 그림 4는 이러한 문 제의 예를 보여준다. 그림 4(a)에 나타난 것과 같이 영상 평면상의 벡터 $\mathbf{v}$ 는 서로 다른 높이 (또는 카메라로부터의 깊이)를 갖는 실공간의 다양한 움직임으로부터 발생하는 것이 가능하다. 그림 4(b)와 같이 관측된 움직임 벡터들이 있다고 할때 이는 그림 4(c) 또는 (d)와 같이 보행자의 서로 다른 부분에서 발생한 것일 수 있다.

이러한 문제를 해결하는 가장 쉬운 방법은 단순히 $h_{e}$ 를 적절한 상수로 설정하는 것이다. 수식 (3)의 $h_{e}$ 의 값을 영상 내 모든 움직임 벡터의 정확한 $h_{e}$ 값의 평균으로 설정할 수 있으면, 이동 속도를 적절히 측정하는 것이 가능할 것이다. 하지만, 모든 움직임 벡터의 $h_{e}$ 값은 영상에 따라 변경될

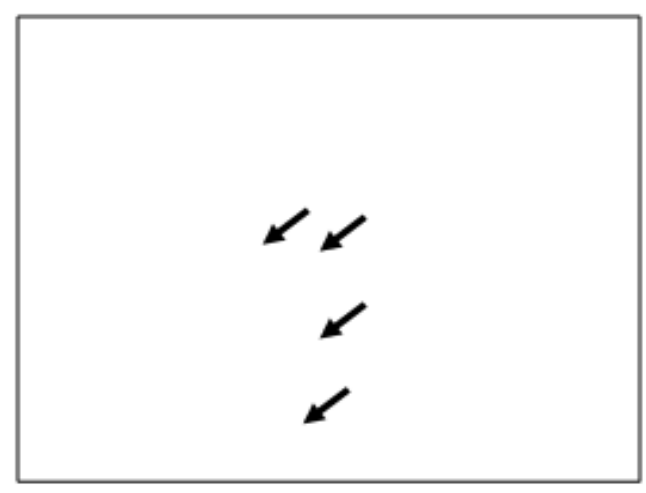

(b)

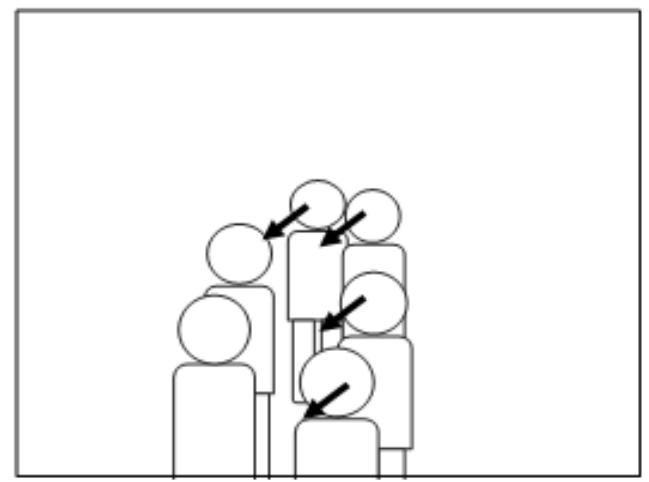

(d)

그림 4. 카메라 투영에 의한 움직임 벡터의 모호성

Fig. 4. Ambiguity of motion vectors due to camera projection 
수 있으므로 하나의 상수로서 적절한 $h_{e}$ 값을 설정하는 것 은 용이하지 않다.

본 논문에서는 적절한 $h_{e}$ 의 값을 시뮬레이션 실험을 통 하여 통계적으로 예측하는 방법을 이용하였다. 이에 앞서 우선 관측된 움직임 벡터들의 실공간 내 높이의 평균값에 영향을 주는 요소들에 대해 고려한다. 그림 5 는 같은 방향 으로 이동하고 있는 두 사람에 대해서 움직임이 관측되는 예를 보여주고 있다. 그림에서 회색으로 표현된 영역에서 발생한 움직임은 앞의 보행자에 의한 가려짐에 의해서 영 상에서 관측되지 않는다. 두 번째 보행자에 대해서 영상에 서 관측 가능한 영역은 $d / \tan \theta$ 로 표현될 수 있다 ( $d$ 는 두 사람 사이의 거리, $\theta$ 는 관찰되는 화소에 대한 기울기 각도). 관측 가능한 영역이 줄어들게 되면, 영상 내에서 관측된 움 직임 벡터는 대부분 보행자의 윗부분에서 얻어지게 되므로 $h_{e}$ 의 평균치는 높아지게 된다.

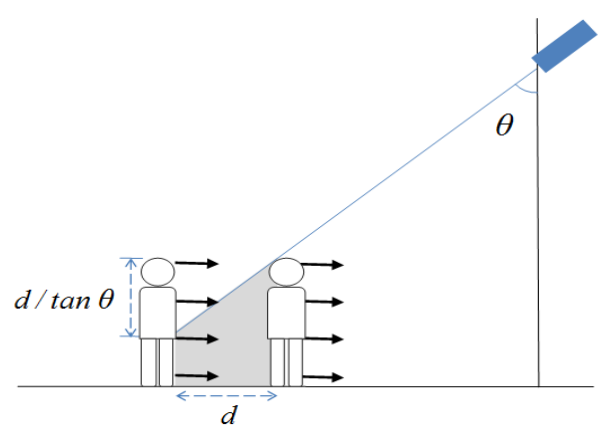

그림 5.보행자 간 거리, 카메라 각도와 가려짐 간의 관계

Fig. 5. Relationship between the amount of occlusion, inter-person distance and camera angle

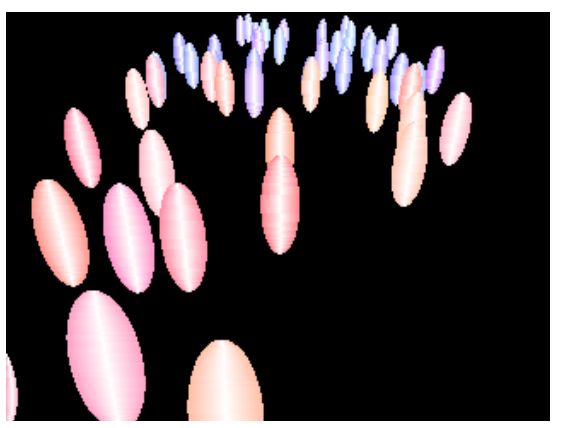

(a)
따라서 영상 내에서 관측된 움직임 벡터가 실공간에서 갖는 높이의 기대치는 다음의 수식 (6)에 나타난 것과 같은 관계를 갖는 것으로 생각할 수 있다. 여기에서 $c r$ 은 단위 면적 내 보행자의 수로 정의되는 군중 밀도(crowd density) 를 나타낸다. 영상 내 사람의 숫자가 많을수록 보행자 간 평균 간격 $d$ 는 줄어들게 되므로 $d$ 와 $c r$ 은 반비례 관계에 있 다. 또한 $c r$ 은 면적에 의한 값이므로 거리 $d$ 와는 제곱으로 비례하는 관계에 있다.

$$
E\left[h_{e}\right] \propto \frac{1}{d / \tan \theta} \propto \tan \theta \sqrt{c r}
$$

수식 (6)에 나타난 것과 같이 영상 내 움직임 벡터의 실 공간 내 평균 높이는 관측 각도와 군중밀도의 함수로 표현 될 수 있다. 본 논문에서는 실공간에서 발생한 움직임의 높이를 추정하기 위하여 합성 영상(synthetic image)를 이 용한 모의 비디오 영상(simulated video)를 이용하였다. 이 모의 비디오는 영상 내 보행자를 타원면으로 표현하고 보 행자의 움직임을 Teknomo에 의해 제안된 미세 보행자 모 델(microscopic pedestrian model)에 의해 제어함으로서 생 성되었다 ${ }^{[12]}$. 실험을 위하여 다양한 카메라 각도와 군중 밀 도를 갖는 약 10,000 장의 영상이 이용되었다. 그림 6은 실 험에 이용된 모의 비디오 영상의 예를 보여준다.

이렇게 생성된 모의 영상에 대하여 군중 밀도와 카메라 각도, 관측된 화소들의 실공간에서 높이의 평균값을 측정 하였으며, 그 결과를 카메라 각도와 군중 밀도의 2차 함수

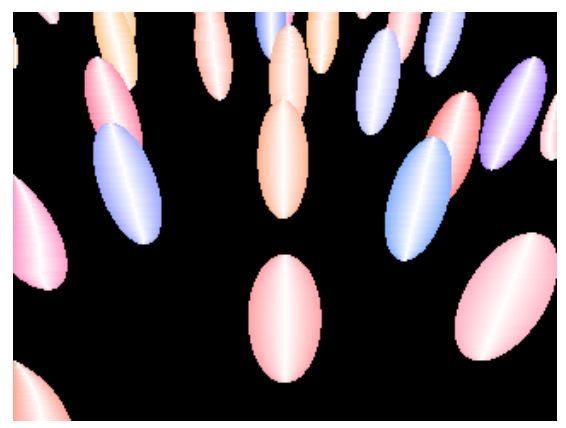

(b)

그림 6. 시뮬레이션 실험을 위한 서로 다른 카메라 각도와 군중 밀도의 합성 영상의 예

Fig. 6. Synthetics image of different camera angles and crowd densities for simulation experiments 
로 적합(fitting)하여 높이 정보를 예측하는 함수를 생성하 였다. 그림 7은 데이터 적합의 결과로 얻어진 2차 함수를 보여준다. 그림 7에서 훈련된 함수가 카메라의 기울기의 변 화에 대해서는 tangent 함수와 유사한 경향을 보이며 군중 밀도 변화에 대해서는 제곱근 함수 형태로 변화함을 볼 수 있는데, 이는 수식 (6)에 나타난 관찰과 일치하는 것임을 알 수 있다.

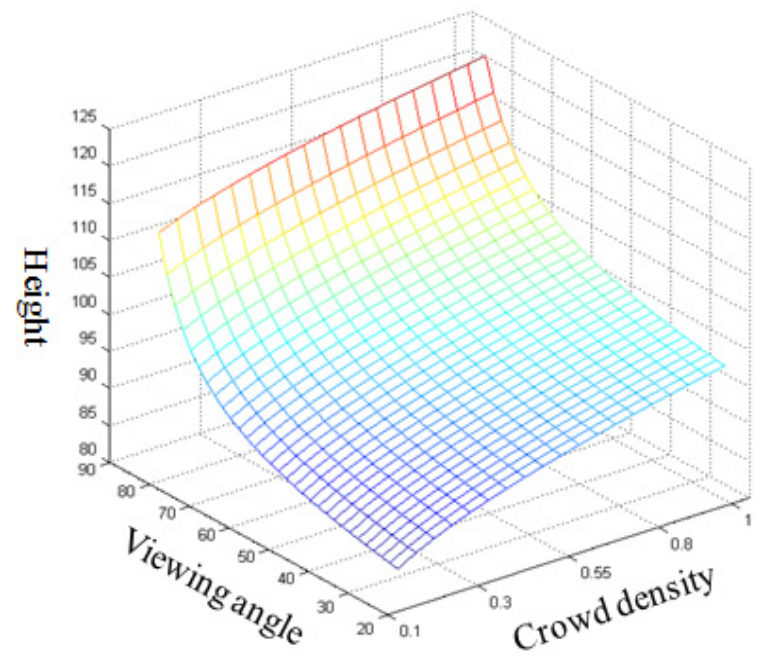

그림 7. 합성 영상들로부터 훈련된 높이 예측 함수의 예

Fig. 7. Height estimation function trained from synthetic images

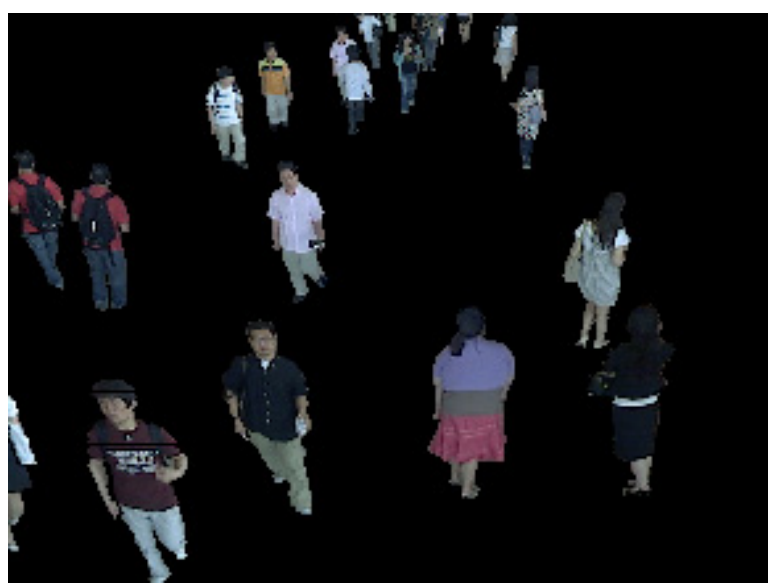

(a)

\section{V. 실험 결과}

이 장에서는 제안된 유동 속도 측정 방법의 실험 결과를 제시한다. 유동 속도 측정의 실험에 있어서 가장 어려운 점 은 많은 사람들이 이동하는 실제 영상에 대해서는 보행자 들의 정확한 이동 속도를 알기가 어렵다는 것이다. 이에 본 논문에서는 합성 영상과 실제 영상의 두 가지 종류의 데이 터에 대하여 실험을 진행하였다. 합성 영상의 생성을 위해 IV장에서 언급된 모조 영상 생성과 같은 보행자 모델을 이 용하였으며, 타원면 대신에 실제 영상에서 획득된 사람 영 상을 이용하였다. 그림 8은 합성 영상과 실제 영상의 예를 보여준다.

그림 9는 합성 영상에 대한 유동 속도 측정 결과를 보여 준다. 합성 영상에서는 각 영상 프레임에 대해서 보행자의 정확한 위치를 알 수 있기 때문에 정확한 이동 속도를 획득 하는 것이 가능하다. 실험을 위해 서로 다른 각도 (30도, 45 도, 60 도)에서 생성된 합성 영상이 이용되었다. 표 1 은 합성 영상에 대한 평균 오차를 측정한 결과이다. 측정 결과 제안된 방법이 약 5 7\%의 상대 오차로 유동 속도를 측정할 수 있음을 확인하였다. 실험 결과 30 도와 45 도의 카메라 각 도에서 영상에 대해서는 군중밀도가 증가함에 따라 오차가 증가하는 경향을 보인 것에 반해, 60 도의 카메라 각도에서 생성된 영상에서는 군중밀도가 낮을때 오차가 큰 경향을

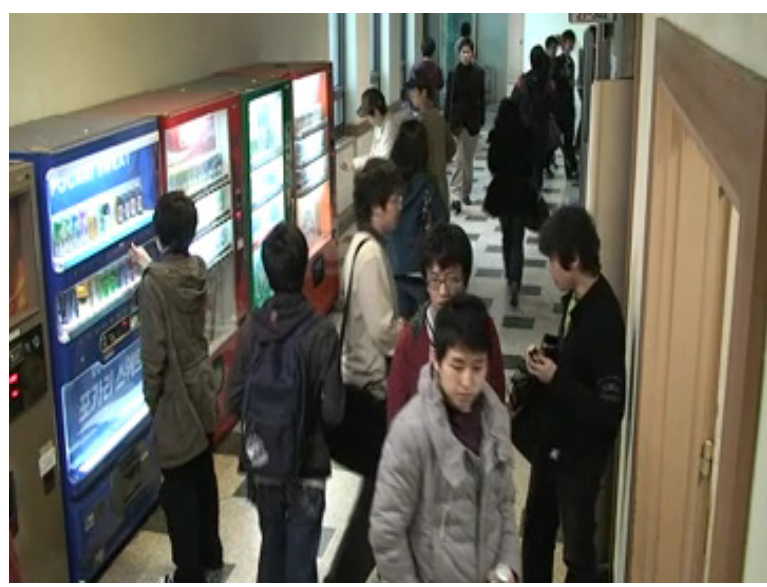

(b)

그림 8. 실험에 사용된 영상의 예: (a) 합성 영상, (b) 실제 영상

Fig. 8. Examples of (a) a synthetic image and (b) a scene from the real video for experiments 


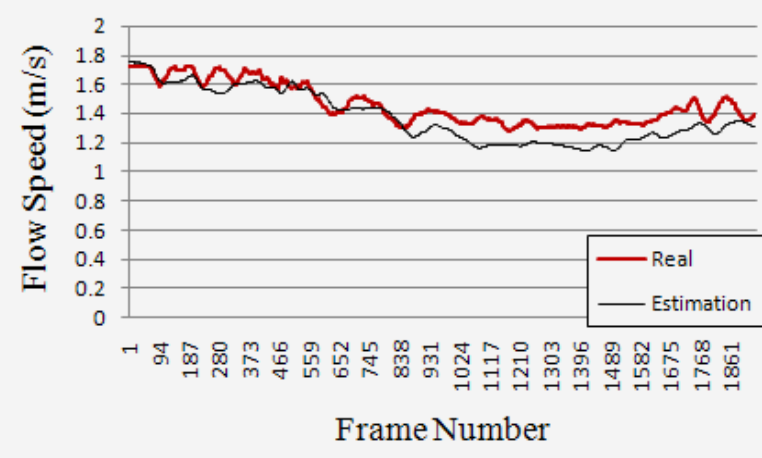

(a)

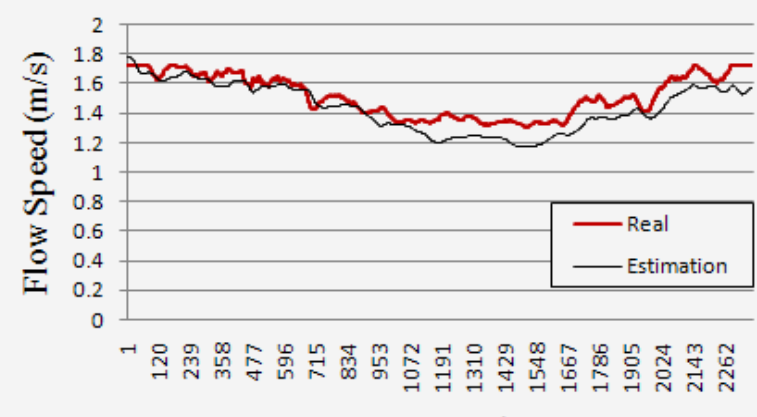

Frame Number

(b)

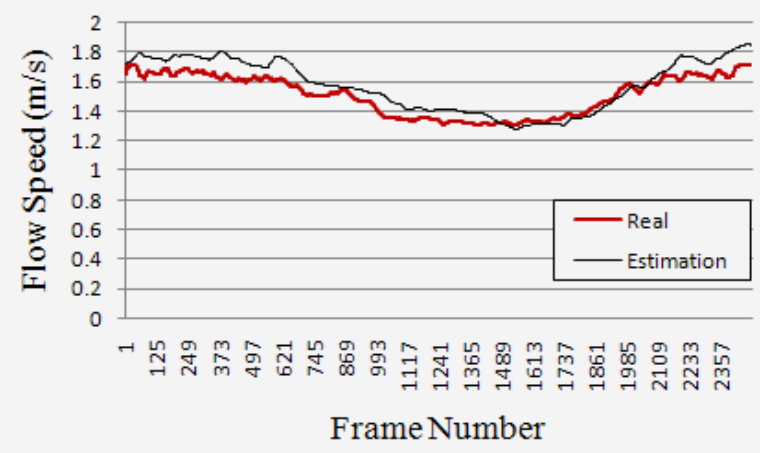

(c)

그림 9. 시뮬레이션 영상에 대한 실험 결과: (a) 30도, (b) 45도, (c) 60 도 Fig. 9. Experiment results for synthetic image sequences with camera tilt angle of (a) $30^{\circ}$, (b) $45^{\circ}$ and (c) $60^{\circ}$

보이는 것을 알 수 있었다. 이는 2 차함수의 형태로 적합된 높이 예측함수가 실제로 기대되는 평균 높이 값과 차이를 보임을 의미하며, 이러한 오차는 예측 함수의 추정을 위해 생성된 데이터의 분포가 고르지 못한데서 발생한 것으로
생각된다. 따라서, 향후 밀도가 다른 훈련 데이터에 대해서 도 강인하게 예측함수를 적합시킬 수 있는 방법에 대한 연 구가 요구된다.

표 1. 합성 영상에 대한 유동 속도 측정 결과

Table 1. Experimental results on synthetic video

\begin{tabular}{|c|c|c|}
\hline & 절대오차 & 상대오차 \\
\hline 30도 & $0.092 \mathrm{~m} / \mathrm{s}$ & $6.52 \%$ \\
\hline 45도 & $0.083 \mathrm{~m} / \mathrm{s}$ & $5.59 \%$ \\
\hline 60도 & $0.072 \mathrm{~m} / \mathrm{s}$ & $4.72 \%$ \\
\hline
\end{tabular}

그림 10 은 실제 영상에 대한 이동 속도 측정 결과를 보여 준다. 실제 영상에 대해서는 정확한 이동 속도를 측정하는 것이 어렵기 때문에 영상 내 보행자의 머리 위치를 수작업 에 의해 추적하고, 이 위치를 카메라 기하에 의해 역으로 투영시킴으로서 각 보행자의 실제 위치를 추정하였다. 이 수작업에 의한 속도 추정은 500 프레임마다 이루어졌다. 그 림 10 의 실선은 제안된 방법에 의해 측정된 유동 속도를 보여주며, 붉은 사각형은 수작업에 의해 측정된 보행자들 의 평균 이동 속도를 나타낸다. 실제 상황에서는 보행자들 의 정확한 이동 속도를 측정할 수 없기 때문에 정확도를 정략적으로 측정하기는 어렵지만, 제안한 방법이 실제 영 상에 대해서도 의미있는 결과를 보여줄 수 있음을 확인하 였다.

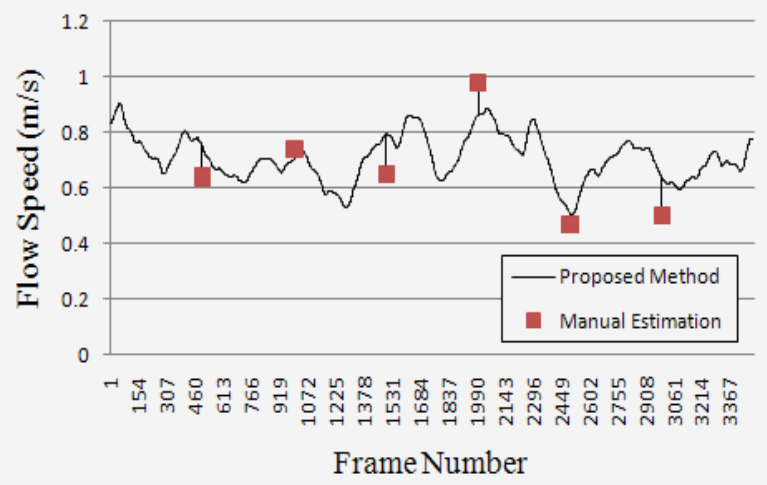

그림 10. 실제 영상에 대한 실험 결과

Fig. 10. Experimental result for the real video 


\section{VI. 결 론}

본 논문에서는 보행자들의 유동 속도를 측정하기 위한 방법을 제안하였다. 제안한 방법은 연속한 프레임 간에 관 측된 움직임 벡터의 실공간의 크기를 예측하고, 그 평균을 통해 영상 내 보행자들의 평균 이동 속도를 측정한다. 이를 위해 화소-미터 변환 인자가 정의되었다. 또한, 관측된 움직 임 벡터의 실공간에서의 높이 정보를 예측하기 위하여 합 성 영상을 이용한 시률레이션 실험이 이용되었다. 제안한 방법은 변환계수 계산 과정에서 카메라 매개변수를 명시적 으로 분리하고 시뮬레이션 실험을 다양한 각도에서 얻어진 영상에 대해 수행하였기 때문에, 기존에 제안된 방법과 달 리 카메라 기하의 변화에 적응적으로 대응 가능한 장점이 있다. 실험을 위해 합성 영상과 실제 영상 두 종류의 데이터 셋을 이용하였으며, 다양한 각도에서 얻어진 합성 영상에 대한 실험 결과는 제안된 방법이 평균 약 $0.08 \mathrm{~m} / \mathrm{s}$ 의 오차로 유동 속도를 측정 할 수 있음을 보여주었고, 또 실제 영상에 대한 실험 결과도 제안한 방법이 감시 영상에 대한 유동 속도에 효과적으로 이용될 수 있음을 보여주었다. 하지만, 실제 영상에 대한 실험은 보행자들의 정확한 이동 속도를 측정하는 것이 어렵기 때문에 그 정확도 검증에 있어서 한 계를 가지고 있다고 할 수 있다. 때문에 향후 연구로써 더 다양한 상황 및 환경을 포함한 영상을 대상으로 제안한 방 법에 대한 검증과 함께 분석이 이루어져야 할 것이다.

\section{참 고 문 헌}

[1] D. Kong, D. Gray and H. Tao, "A Viewpoint Invariant Approach for Crowd Counting," in Proceedings of International Conference on Pattern Recognition, vol. 03, pp. 1187-1190, 2006

[2] H. Rahmalan, M. Nixon, and J. Carter, "On Crowd Density Estimation for Surveillance" The Institution of Engineering and Technology Conference on Crime and Security, p. 540-545, 2006

[3] H. Celik, A. Hanjalic and E. A. Hendriks, "Towards a Robust Solution to People Counting," International Conference on Image Processing, pp. 2401-2404, 2006

[4] S. A. Velastin, B. A. Boghossian, B. P. L. Lo, S. Jie, M. A. Vicencio-Silva, "PRISMATICA: toward ambient intelligence in public transport environments," Tans. on Systems, Man and Cybernetics, vol. 35, issue 1. pp.164-182, Jan. 2005.

[5] F. Porikli, Y. Ivanov and H. Taga, "Robust abandoned object detection using dual foregrounds," EURASIP Journal on Advances in Signal Processing, vol. 2008, Issue 1, No. 30, pp. 1-11, 2008.

[6] P. A. Thompson and E. W. Marchant, "Simulex; Developing New Computer Modeling Techniques for Evaluation," Fire Safety Science, vol. 4, pp. 613-624, 1994.

[7] G.-G. Lee, B. Kim, W.-Y. Kim, "Automatic Estimation of Pedestrian Flow," International Conference on Distributed Smart Cameras, pp. 291-296, 2007.

[8] K. Teknomo, Y. Takeyama, and H. Inamura, "Tracking system to automate data collection of microscopic pedestrian traffic flow," in Proceedings of The 4th Eastern Asia Society For Transportation Studies. 2001. p. 11-25.

[9] Y. Li, B. Wu and R. Nevatia, "Human Detection by Searching in 3D Space using Camera and Scene Knowledge," International Conference on Pattern Recognition, pp. 1-5, 2008.

[10] C. Beleznai, B. Fruhstuck and H. Bishof, "Human Tracking by Fast Mean Shift Mode Seeking," Journal of Multimedia, vol. 1, no. 1, pp.1-8, April 2006

[11] T. Shimmura, H. Arai, and U. Inoue, "Estimating human-flow speed for video surveillance by probabilistic stands," in Cybernetics and Intelligent Systems, vol 1, pp. 179-184, Dec. 2004.

[12] K. Teknomo, "Microscopic Pedestrian Flow Characteristics: Development of an Image Processing Data Collection and Simulation Model," Ph.D. Dissertation, Tohoku University, 2000.

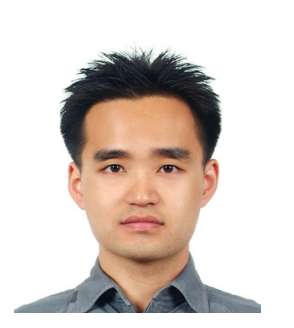

\section{이 광 국}

- 2002년 : 한양대학교 전자전기공학부 학사

- 2004년 : 한양대학교 전자통신전파공학과 석사

- 2004년 현재 : 한양대학교 전자컴퓨터통신공학과 박사과정

- 주관심분야 : 영상감시, 패턴인식, 내용기반 멀티미디어 분석 
저 자 소 개

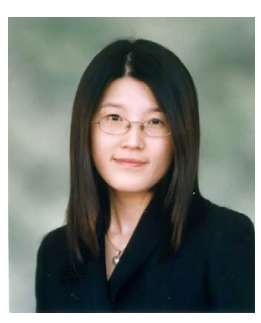

\section{윤 자 영}

- 2004년 : 한양대학교 건축공학부 학사

- 2005년 현재 : 한양대학교 건축환경공학과 석.박사 통합과정

- 주관심분야 : Building Information Modeling (BIM), 공간정보관리, 경영 시스템

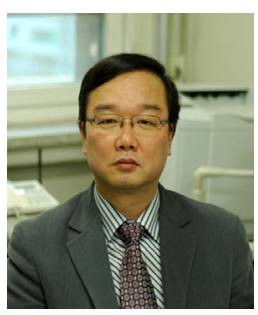

\section{김 재 준}

- 1983년 : 한양대학교 건축공학과 학사

- 1985년 : University of Illinois at Urbana-Champaign 건설관리 공학석사

- 1992년 : University of Illinois at Urbana-Champaign 건설경영/관리 공학박사

- 1993년 현재 : 한양대학교 건축공학부 교수

- 주관심분야 : Building Information Modeling (BIM), 시스템경영, 건설자동화

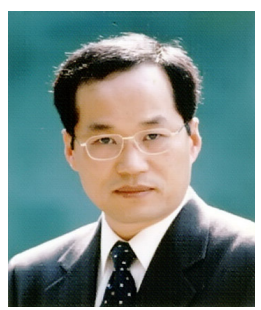

\section{김 회 율}

- 1980년 : 한양대학교 전자공학과 졸업 (공학사)

- 1983년 : Pensylvania State University 전기공학과 졸업 (공학석사)

- 1989년 : Purdue University 전기공학과 졸업 (공학박사)

- 1989년 9월 1994년 2월 : University of Texas 조교수

- 1994년 현재 : 한양대학교 전자통신컴퓨터공학부 교수

- 주관심분야 : 영상처리, 컴퓨터비전, 패턴인식, 머신비전, MPEG-7등 